\title{
TV COMUNITÁRIA NOS EUA
}

\section{Conselho Comunitário tem autonomia na gestão dos canais comunitários por cabo nos EUA, recebe recursos financeiros de empresas do setor e do governo local}

O sistema de TVs de acesso público nos Estados Unidos é um fenômeno de pouco conhecimento no Brasil. No momento em que aparecem as primeiras TVs Comunitárias via cabo no país, por sinal inspiradas na legislação dos Estados Unidos, o modelo norte-americano pode dar algumas diretrizes do caminho a seguir e algumas a evitar.

Parto de uma identidade com as TVs de acesso público porque elas se organizaram e se sustentam como movimento social. Originaram-se no início dos anos 70, a partir de dois componentes: a contracultura, como conseqüente oposição aos meios de comunicação de massa; e o advento do vídeo portátil. Nessa efervescência cultural, com o apoio das operadoras de cabo então nascentes e com canais disponíveis, logrou-se garantir canais nos quais segmentos da população teriam autonomia para transmitir suas mensagens.

Nas TVs comunitárias, de uma forma geral, há abertura da grade de horários a pessoas ou grupos que desejam colocar suas mensagens no ar. Nada é cobrado, mas também não é permitido retorno comercial. Outras restrições se aplicam: não se pode violar direitos autorais, não é permitido material obsceno, e outras regras que variam de município para município (a legislação de telecomunicações

\section{O AUTOR}

\section{Júlio Wainer}

Professor Doutor da Faculdade de Comunicação da Pontifícia Universidade Católica de São Paulo. nos EUA é local). Por exemplo, algumas cidades impedem programas ligados a partidos políticos; outras, entendendo que partidos menores não têm como comprar horário na TV comercial, os incentivam. A formação de rede - um mesmo produto sendo exibido em vários acessos públicos locais - é restrita. Com isto, pretende-se evitar a formação de verdadeiros impérios, ainda que sob a égide da nomenclatura não-governamental, emissoras que se travestem em religiosas ou beneméritas mas, em última instância, objetivam a expansão de seu ideário.

Não obstante, uma organização com sede na cidade pode produzir a sua versão de um programa, para o qual não haverá nenhum tipo de censura ideológica. Levado a ferro e fogo, este princípio permite que grupos ligados à Ku Klux Klan, por exemplo, tenham programas na TV comunitária, sob o olhar constrangido dos funcionários e do conselho gestor, via de regra identificados (e motivados) com as causas progressistas da sociedade.

Um grupo pequeno de funcionários mantém a TV operando. A mão-de-obra dos programas é voluntária, cabendo aos grupos interessados arregimentar seu time que, uma vez capacitado tecnicamente pelo canal, produzirá a meia hora semanal daquela organização.

Com o tempo, as negociações tripartite (comunidade/ governo local /operadora de cabo) evoluíram, e logrou-se um sistema de financiamento para garantir a existência e crescimento do sistema de acesso público. 
O sistema de TV a cabo, como se sabe, tornou-se um big business nos Estados Unidos. Sendo a concessão um monopólio, franqueado pela prefeitura municipal, exigiu-se como contrapartida uma dotação orçamentária que possibilite a manutenção do canal. Ainda que seja generosa para os padrões brasileiros, ela não é suficiente para a manutenção do sistema. Então, buscam-se recursos complementares em outras fontes: governo local, sistema de ensino, sistema de saúde etc. A somatória desses recursos vai para o que se convencionou chamar Acesso PEG - Público (comunitário), Educacional e Governamental (câmara e executivo municipal) -, cada um com um ou mais canais, cada um com seu orçamento.

\section{CANAL COMUNITÁRIO E INTERESSES DA COMUNIDADE}

$\mathrm{O}$ sistema se originou em Nova York e se espalhou por todo o país. Hoje a Alliance for Community Media (www.alliancecm.org) - organização que congrega as TVs de acesso público (na verdade, os PEG) - estima que existam duas mil emissoras de tamanhos muito diferenciados. Há desde aquela que funciona em uma igreja, e que fecha às 18 horas, até centros que administram seis canais de televisão, rádio comunitária e centros de computadores de livre acesso pela população.

Há poucos anos expirou a franquia de concessão do cabo em Manhattan, distrito de Nova York, e se logrou uma negociação bastante favorável com a Time Warner, operadora de cabo local. A companhia se dispôs a dotar a estação Manhattan Neighborhood Network, (www.mnn.org) com 2,9 milhões de dólares por ano. Com esse dinheiro, se dá apoio a quatro canais, 24 horas/dia, a programas de treinamento ao longo de todo o distrito (pois uma estação centralizada não alcança de fato toda a comunidade) e à manutenção do Centro de Mídia. Na mesma cidade funcionam outros sistemas de TV via cabo: no Brooklin, Queens e Staten Island, cada um com seus canais de acesso público.

São os Centros de Mídia que garantem a existência da TV comunitária. Eles são facilitadores da produção de programas por grupos sociais.

Nestes Centros de Mídia a população tem equipamentos à disposição (câmeras, ilhas de edição, computadores) que podem ser usados sem custos; tem instalações adequadas (um, dois, três estúdios prontos para funcionamento pelos voluntários); e capacitação para utilização plena desse arsenal produtivo. $O$ orçamento anual (um valor médio de US\$ 700.000) deve ser suficiente para custear um grupo de funcionários (uma dúzia, por exemplo), pagar todos os custos de manutenção da Estação e ainda comprar novos equipamentos (geralmente uma rubrica em separado). A gestão do canal é feita por um Conselho, não remunerado, representativo da comunidade local. É esse grupo que aprova as regras, contrata o corpo técnico e dá a direção política da organização.

Os programas dos canais públicos representam o universo de interesses da comunidade. Existe o trivial-local (festejos, esporte corporativo, referenciais culturais regionais), o religioso (todo e qualquer agrupamento religioso certamente terá seu programa), a representação por minorias étnicas ou nacionalidades (são vários os programas sobre o Brasil), os grupos de interesses diversos (ecologia, esoterismo, homossexualismo), outras organizações de interesse público (associações, sindicatos, institutos), bem como hobbystas de 
música, colecionadores, amantes da natureza etc. Diversos são os programas de educação não-formal. Há, ainda, programas de oposição, que se preocupam em mostrar uma realidade social/política e econômica que as redes comerciais não ousam. Organizações como o Deep Dish (www.deepdish.org) lançam temas de discussão da sociedade americana e recolhem matérias em todo o país. Estas matérias são agrupadas em conjuntos (por exemplo, 12 reportagens sobre Violação dos direitos humanos nos EUA), fazendo um programa de uma hora e são transmitidos por satélite para as TVs comunitárias em horários bem mais baratos.

O princípio de preenchimento da grade é: first come first served basis (o primeiro a chegar, o primeiro a ser atendido). Há, no entanto, quem defenda uma atitude mais propositiva por parte dos gerenciadores do canal comunitário.

Uma sociedade imersa na mensagem televisual (fato normalmente associado à passividade), mas produtiva e participativa, proporcionou uma quantidade de voluntários realizadores de programas em um volume inimaginável.

A qualidade técnica dos programas é, naturalmente, baixa; a audiência, pouca (bons programas comunitários acabam migrando para TVs comerciais). O significado social e antropológico, no entanto, é tremendo. As mudanças, às vezes invisíveis no atacado, aproximam os gêneros (inclusive com o aumento sensível de mulheres na vida pública); constroem pontes entre comunidades isoladas; integram cidadãos à vida comunitária; elegem prefeitos e vereadores sem recursos, mas comprometidos com os interesses da população; barram empreendimentos imobiliários milionários; aproximam vizinhos de uma mesma comunidade.

É com base no pressuposto da importância social que vozes do interior do movimento vêm sugerindo mudanças. George Stoney é con- siderado o pai das TVs comunitárias e um de seus mais influentes ideólogos. Representa também o encontro das TVs comunitárias com o Movimento Documentarista em seu esforço de trazer ao público vozes autenticamente populares. No discurso de abertura da $23^{\mathrm{a}}$. Conferência Anual, em julho de 1999, Stoney afirmou: "se temos dificuldades financeiras é porque não aprendemos a cobrar dos que ganham com os programas, a começar das igrejas". Em outro momento, em conversa mais reservada, questionou a razão de ser dos canais de acesso público: "Incomoda-me essa serventia toda a que os canais se entregam. As TVs são uma ferramenta de transformação social, e como tal devem ter uma orientação. Alguns programas deveriam ser encorajados, alguns temas teriam de ser abordados com mais frequiência, alguns grupos com alto potencial de transformação, como associações de pais e mestres por exemplo, deveriam ser alvo de uma estratégia de envolvimento no canal e na programação". Enfim, o papel de isenção, de guardião da liberdade da iniciativa alheia à que se propõem os dirigentes dos canais começa a ser questionado.

Isto se dá também no contexto das mudanças na sociedade a que assistimos a partir de meados dos anos 80 .

Nos Estados Unidos, como aqui, a terceira via só vinga no discurso político do exterior; via de regra, venceu a orientação voltada ao capital. A sociedade está mais estratificada, o critério econômico passou a ser cada vez mais preponderante. A promessa de integração racial, horizonte possível dos anos 70, não se instalou na sociedade norte-americana. Aqui no Brasil, apesar da democracia formal, a renda se concentrou, a violência se instituiu, o poder popular está enfraquecido. Ganhamos, se posso dizer assim, algumas batalhas importantes mas perdemos a guerra até agora.

Aqui, como lá, só vemos a possibilidade de uma transformação radical a partir do 
trabalho educativo. Uma missão a longo prazo, transformadora de mentes acomodadas, que questiona o consumismo, a mídia e alguns pressupostos viciados desde a formação dada pelos próprios pais.

\section{TV DE ACESSO EDUCACIONAL}

Nos EUA, do tripé acesso público/ acesso governamental/ acesso educacional é este último que vem crescendo com mais intensidade. Sistemas educativos investem na TV como uma ocupação importante para o aluno em seu tempo livre. Muitos programas oferecem educação complementar do que é ensinado na escola (ensino fundamental e médio), geralmente ao vivo, possibilitando que a audiência intervenha com perguntas por telefone. Programas em forma de jornalismo e entretenimento (talk show) esclarecem sobre temas como metodologia pedagógica, papel dos pais, currículo. Os professores têm oportunidade de se reciclar com programas protagonizados por excelentes profissionais (um conselheiro da TV de Boulder, Colorado, conta que por vezes cientistas detentores do prêmio Nobel, residentes na cidade, foram à TV esclarecer teorias científicas em voga), exatamente o que aqui se convencionou chamar de educação continuada. Ou, ainda, a TV é oferecida como opção de profissionalização (estudantes do nível médio de Lubbock, Texas, optam entre esportes, artes ou produção de TV, alimentando uma estação feita por jovens e para jovens 24 horas no ar).
Não se trata apenas de produzir mãode-obra habilitada para trabalhar em televisão. Trata-se de desenvolver habilidades de comunicação visual e escrita, trabalho em grupo e envolvimento nas questões da escola e da comunidade. Proporcionar uma alfabetização visual, onde o educando possa ler a TV de forma crítica, e também escrever sua própria história e seus interesses.

Separados muitas vezes por uma circunstância contratual, a reunião do público com o educacional e o governamental em uma só iniciativa é um desejo freqüente. Primo pobre, o público tem no educacional a possibilidade de continuidade e transformação social a longo prazo; e no governamental uma chance mais próxima de influir nas políticas públicas.

O educacional teria no público uma oportunidade de ligar a letra morta com temas efetivamente significantes para o educando, numa abordagem freireana ${ }^{\prime}$ de educação. Ensinar Geografia a partir do entorno; História com os grupos étnicos da comunidade; Gramática e Matemática com referências locais e assim por diante.

Esse casamento não é fácil e imediato. Tema de várias das sessões da Conferência da The Alliance, de 1999, em Cincinnati, as dúvidas variavam no tocante ao custo do aluno/ano. No caso de ensino de vídeo para jovens da escola pública, seria necessário planejar horários especiais que não conflitassem com os dos usuários normais dos Centros de Mídia; transporte esco-

1. Referência do autor ao educador brasileiro Paulo Freire e a seu sistema pedagógico. (N. Ed.) 
la/centro de mídia e metodologia de ensino de vídeo, entre outros.

Outra preocupação presente reside no acordo que viabiliza um acesso educacional forte, contando com a participação de organizações tão diferentes entre si como uma universidade privada, o sistema de ensino fundamental público, secretaria de educação, pais e professores, museus e atrações educacionais, como um zoológico. Pela participação no bolo do canal, cada entidade ganha direito a seu programa e ainda contribui com programas genéricos de caráter informativo educacional.

Experiências bem-sucedidas nesta costura institucional ganham espaço nos workshops da Conferência Anual e são divulgadas no boletim trimestral Community Media Review (editado pela Alliance for Community Media).

O Tampa Educational Cable Consortium, por exemplo, localizado na Flórida, (www.innet.com/-educate), reúne 17 entidades

Resumo: As TVs comunitárias nos Estados Unidos constituem-se em movimento social autêntico e extremamente representativo. Os Centros de Mídia dão apoio aos canais comunitários mediante a produção de programas e formação de equipes, custeado por recursos provenientes das empresas que detêm o monopólio municipal da exploração do serviço a cabo, pelo governo local e outras entidades. O Tripé PEG, com canais públicos (comunitário), educacionais e governamentais, todos na escala municipal, tem repercussão direta na mudança das relações locais e nos processos educativos formais e não-formais.

Palavras-chave: TV comunitária, Estados Unidos, canal público, programa educativo, TV a cabo e produz 10 programas originais, exclusivos para a localidade. Tem destaque o programa de leitura para jovens, com contadores de histórias, ganhador de vários prêmios.

Acordos com TVs educativas, como a NASA TV, viabilizaram um programa do Ministério da Educação que ganha debate local após exibição em rede, entre outros programas artístico-culturais que completam a grade horária.

Sacramento Educational Cable Consortium (canais 71 e 72 de Sacramento, Califórnia), www.secc-tv.org, prepara eventos que aprofundam o uso do vídeo como ferramenta de educação a distância. Cable in the Classroom Media Fests reúne professores com representantes do sistema de cabo para debater sobre a programação para a sala de aula. Student Educational Video Awards é uma competição entre estudantes, aprovada por estudantes e profissionais pela originalidade e conteúdo.

Abstract. Community TVs in the United States are an authentic and extremely representative social movement. Media Centers support community channels through the production of programs and team training. These activities are financed by resources coming from the companies that detain the municipal monopoly on cable service exploitation, from local government and from other entities. The PEG tripod, with public channels (community), educational and governmental channels, all on the municipal scale, has direct repercussion on changing local relations and on the formal and non-formal educational processes.

Key words: Community TV, United States, public channel, educational program, cable TV 